\title{
Adult-onset bulbar ptosis in Joubert syndrome
}

This article was published in the following Dove Press journal:

Clinical Ophthalmology

23 January 2012

Number of times this article has been viewed

\section{Benjamin Burt \\ Johanan Levine \\ Kim Le \\ Texas Tech University, Department of Ophthalmology, Paul L Foster School of Medicine, El Paso, Texas}

Correspondence: Benjamin Burt Tel +l 9493947933

Email Benjamin.burt@ttuhsc.edu
Abstract: In this case report, we describe a case of adult-onset bulbar ptosis in a patient with Joubert syndrome. Joubert syndrome is a rare neurodevelopmental disorder with malformations in cerebellum and brainstem. Many ocular abnormalities have been noted in Joubert syndrome, but the association of this syndrome with adult-onset ptosis has not been described to date. This 24-year-old Joubert patient developed a cerebrospinal fluid cyst in her midbrain. She had signs of bilateral third nerve palsy and abducens palsy in the left eye. The bilateral central third nerve palsy causing functional blindness secondary to severe bilateral levator palsy was treated successfully with silicone sling frontalis suspension, as the seventh nerve nucleus was not involved.

Keywords: Joubert syndrome, ptosis, diplopia, molar tooth formation, silicone sling implants

\section{Introduction}

Joubert syndrome is an autosomal recessive, neurodevelopmental disorder resulting from cerebellar and brainstem abnormalities. This syndrome was first documented in 1969 in five children with episodic tachypnea, jerky eye movements, ataxia, mental retardation, and hypogenesis of the cerebellar vermis. ${ }^{1}$ Magnetic resonance imaging revolutionized the diagnosis of Joubert syndrome. It revealed midbrain/hindbrain malformations including fourth ventricle dilatation and superior cerebellar peduncle elongation, which forms the classically described "molar tooth sign". ${ }^{2}$ Distortion in the eye and brainstem may cause several ocular manifestations of Joubert syndrome, including Leber's congenital amourosis, colobomas, and congenital retinal dystrophy. ${ }^{3}$ Here, we describe one case of a variant form of Joubert syndrome and adult-onset bilateral ptosis.

\section{Case history}

The 24-year-old female patient complained of double vision and the inability to open both eyes for the past 6 months. She denied the presence of headaches and seizures. The onset of the ptosis had slowly progressed, starting a year prior after the mother noticed her daughter's unequal pupils. The mother reported that her daughter had twitching and gradual closure of her right eye that spread to the left eye within 6 months (Figure 1).

The patient's past medical history is significant for premature birth at 28 weeks gestation with corpus callosum agenesis, cerebellar vermis agenesis, a molar tooth-like 


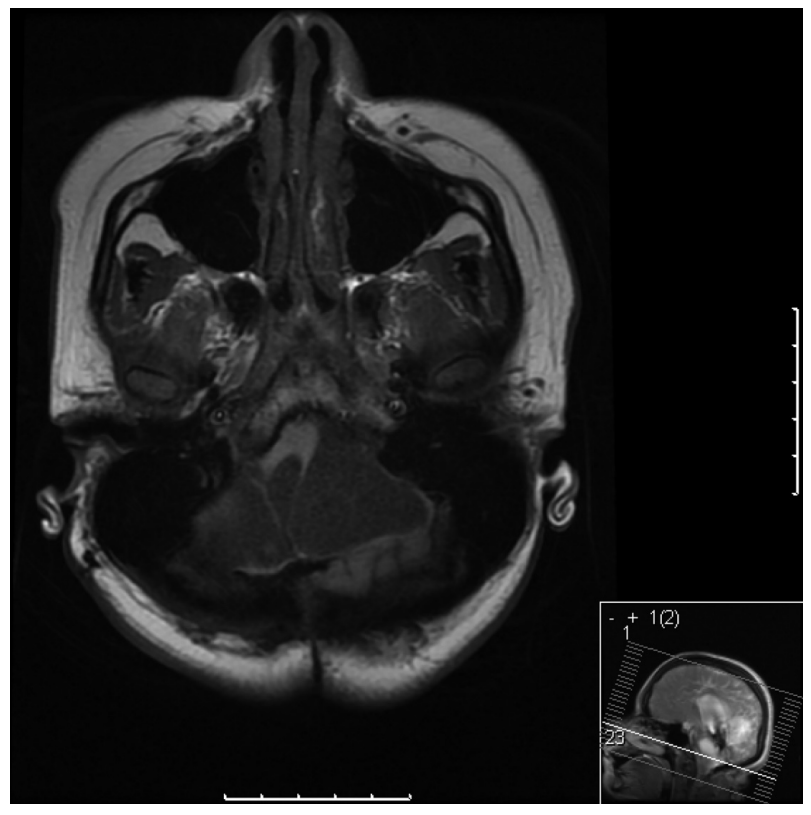

Figure I Baseline magnetic resonance imaging without contrast. The skewed molar tooth sign can be visualized.

brainstem, and a cyst in her midbrain. In her first week of life, she developed an interventricular hemorrhage that caused hydrocephaly and required ventriculoperitoneal shunting. The patient received two ventriculoperitoneal shunts, one in the right frontal lateral ventricle and the other in the fourth ventricle. She underwent multiple revisions of the shunts for occlusion, infection, and malfunction in 2002, 2003, and 2005. She had an extensive history of seizures lasting 1-3 minutes, controlled with antiepileptics. Due to abnormal cerebral development, the patient had difficulties swallowing, total left hemiparesis, and spastic muscle tone.

Ocular examination assessed the visual acuity, which was $20 / 80$ for the left and right eye. The patient had diplopia on primary gaze, complete closure of the right eye, and almost complete closure of the left eye. The right eye had an exotropia of 55 prism diopters. The optic nerve appeared pale in both eyes. An extraocular motility examination revealed bilateral upgaze and downgaze palsy and an abducens palsy of the left eye. Neurologic testing displayed spastic motor control and paraplegia, with the right side worse than the left. The patient had a poor finger-to-nose test, with the left worse than the right. The heel-to-shin test was absent on both sides. The patient had over three deep tendon reflexes throughout.

A baseline magnetic resonance image of her brain 6 years prior to her first admission due to shunt malfunction revealed dysgenesis of the corpus callosum with colpocephaly, atrophy of the cerebellar vermis, and a large posterior interhemispheric cyst causing anterior displacement of the diencephalon and third ventricle. The brainstem of the patient did not look like the classical "molar tooth sign." Rather, the molar tooth seemed to be skewed to the left side.

A cystic lesion was located in the right cerebral peduncle, suggesting an entrapped section of the fourth ventricle. After several revisions of both shunts, the frontal shunt tip was placed adjacent to the third ventricle in the region of the right foramen of Monro, and the infratentorial shunt tip placed in the cerebral aqueduct. A computed tomography scan of her head upon admission revealed that the cyst in the right cerebral peduncle had enlarged in size to $11.2 \mathrm{~mm}$.

Due to her diplopia and bilateral ptosis, myasthenia gravis was considered. However, the anti-acetylcholine antibody level results and the ice test were within normal limits. Genetic testing was carried out in suspicion of Dandy Walker malformation, but the results revealed a normal female karyotype.

The patient was brought to the operating room for bilateral ptosis repair with silicone sling implants. Seiff slings (Seiff Frontalis suspension et, Beaver Visitec, Waltham, MA) were inserted and tightened until the upper lid was at maximal height whilst still maintaining globe contact. On a follow-up appointment, the patient was able to open and close her eyes well with frontalis and orbicularis contraction, respectively (Figure 2).

\section{Discussion}

Many ophthalmic features have been associated with Joubert syndrome, such as saccadic dysfunction, primary nystagmus, strabismus, and ptosis. ${ }^{4}$ However, those features were exclusively described in children, whereas our patient developed bilateral ptosis as a young adult. Her ptosis and eye movement dysfunction could be a progression of her Joubert syndrome, or possibly a complication of multiple ventriculoperitoneal shunting.

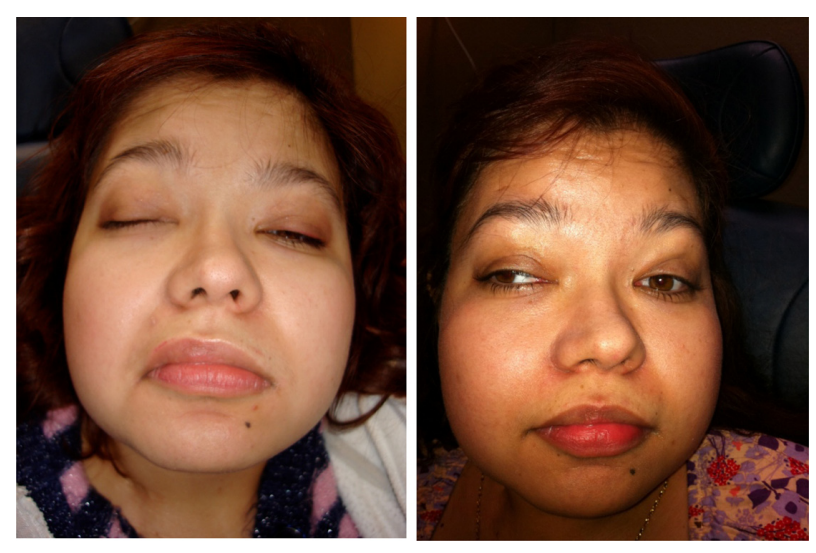

Figure $\mathbf{2}$ The before and after pictures of the patient. 
Her late-onset ptosis could also be a complication of the fibrocystic changes in her midbrain from multiple ventriculoperitoneal shunting. Repeated shunting may also cause further dilatation of the aqueduct, which could disrupt the oculomotor nucleus located anterior to the cerebral aqueduct at the level of the superior colliculi. ${ }^{5}$ The enlarging midbrain cyst adjacent to the posterior shunt tip could also be the cause of her abnormal ocular motility and bilateral ptosis. The abducens palsy of the left eye could be a sign of increased intracranial pressure from shunt malformation. ${ }^{6}$ However, we should have been able to identify papilledema in our patient. There have been documented cases of increased intracranial pressure presenting with an isolated abducens palsy without papilledema. $^{\text {? }}$

Nystagmus is commonly found in Joubert syndrome yet was absent in our patient. Appleton et $\mathrm{al}^{8}$ discussed congenital ocular fibrosis in a patient with Joubert syndrome. Congenital ocular fibrosis is characterized by the abnormal insertion and fibrosis of the extraocular muscles with ptosis and compensatory chin elevation, which could account for our patient's ocular findings. However, the patient's extraocular muscles appeared normal without signs of fibrosis intraoperatively with forced duction testing.

Our patient did not have the classic form of Joubert syndrome. She developed bilateral ptosis as an adolescent, and the cause of the ptosis is still unclear. We present a rare case of central third nuclear ptosis secondary to Joubert syndrome or perhaps its management of cerebrospinal fluid flow blockage. The patent was able to be treated for ptosis effectively with frontalis slings. However, the right extraocular muscle weakness caused ongoing diplopia. To our knowledge, this is the first such case of adult-onset nuclear third nerve palsy in the presence of Joubert syndrome described in the literature.

\section{Disclosure}

The authors report no conflicts of interest in this work.

\section{References}

1. Joubert M, Eisenring JJ, Robb JP, Andermann F. Familial agenesis of the cerebellar vermis. Neurology. 1969;19:813-825.

2. Ferland RJ, Walsh CA. Joubert syndrome. Encyclopedia of Neuroscience. 2009:249-256.

3. Khan AO, Oystreck DT, Seidahmed MZ, et al. Ophthalmic features of Joubert syndrome. Ophthalmology. 2008;11512:2286-2289.

4. Maria BL, Boltshauser E, Palmer SC, Tran TX. Clinical features and revised diagnostic criteria in Joubert syndrome. $J$ Child Neurol. 1999; 14:583-590

5. Carlow T. Oculomotor nerve cranial nerve III. Encyclopedia of the Neurological Sciences. 2003:660-662.

6. Cinciripini GS, Donahue S, Borchert MS. Idiopathic intracranial hypertension in prepubertal pediatric patients: characteristics, treatment, and outcome. Am J Ophthalmol. 1999;1272:178-182.

7. IzciY, Kırık A, Mutlu FM. Transient unilateral ophthalmoplegia without papilledema in a child with intracranial hypertension. Saudi Journal of Ophthalmology. 2010;24:159-162.

8. Appleton RE, Chitayat D, Jan JE, et al. Joubert's syndrome associated with congenital ocular fibrosis and histidinemia. Arch Neurol. 1989;465:579-582.
Clinical Ophthalmology

\section{Publish your work in this journal}

Clinical Ophthalmology is an international, peer-reviewed journal covering all subspecialties within ophthalmology. Key topics include: Optometry; Visual science; Pharmacology and drug therapy in eye diseases; Basic Sciences; Primary and Secondary eye care; Patient Safety and Quality of Care Improvements. This journal is indexed on

\section{Dovepress}

PubMed Central and CAS, and is the official journal of The Society of Clinical Ophthalmology (SCO). The manuscript management system is completely online and includes a very quick and fair peer-review system, which is all easy to use. Visit http://www.dovepress.com/ testimonials.php to read real quotes from published authors. 